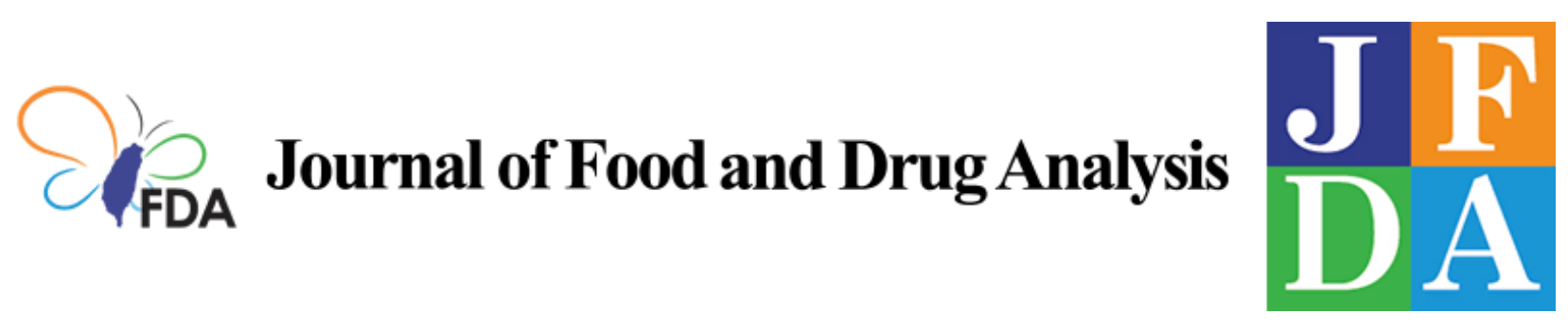

Volume 28 | Issue 2

Article 1

2020

\title{
The potential role of phenolic compounds on modulating gut microbiota in obesity
}

Follow this and additional works at: https://www.jfda-online.com/journal

Part of the Food Science Commons, Medicinal Chemistry and Pharmaceutics Commons, Pharmacology Commons, and the Toxicology Commons

(c) (i) (9)

This work is licensed under a Creative Commons Attribution-Noncommercial-No Derivative Works 4.0 License.

\section{Recommended Citation}

Yen, Gow-Chin; Cheng, Hsin-Lin; Lin, Li-Yu; Chen, Shiuan-Chih; and Hsu, Chin Lin (2020) "The potential role of phenolic compounds on modulating gut microbiota in obesity," Journal of Food and Drug Analysis: Vol. 28 : Iss. 2 , Article 1.

Available at: https://doi.org/10.38212/2224-6614.1054

This Review Article is brought to you for free and open access by Journal of Food and Drug Analysis. It has been accepted for inclusion in Journal of Food and Drug Analysis by an authorized editor of Journal of Food and Drug Analysis. 


\title{
The potential role of phenolic compounds on modulating gut microbiota in obesity
}

\author{
Gow-Chin Yen ${ }^{a}$, Hsin-Lin Cheng ${ }^{\mathrm{b}}$, Li-Yu Lin ${ }^{\mathrm{b}}$, Shiuan-Chih Chen ${ }^{\mathrm{c}, \mathrm{d}}$, Chin-Lin Hsu ${ }^{\mathrm{b}, \mathrm{e}, *}$ \\ a Department of Food Science and Biotechnology, National Chung Hsing University, Taichung, Taiwan \\ ${ }^{\mathrm{b}}$ Department of Nutrition, Chung Shan Medical University, Taichung, Taiwan \\ ${ }^{c}$ Institute of Medicine, Chung Shan Medical University, Taichung, Taiwan \\ ${ }^{\mathrm{d}}$ Department of Family and Community Medicine, Chung Shan Medical University Hospital, Taichung, Taiwan \\ ${ }^{\mathrm{e}}$ Department of Nutrition, Chung Shan Medical University Hospital, Taichung, Taiwan
}

\begin{abstract}
Obesity is a rising public health issue and challenge which is tightly correlated with socio-economic development paralleled with increased energy intake and sedentary behavior that subsequently cause adipose tissue accumulation. Physiological and metabolic status changes during obesity development have been suggested with low grade inflammation of gastrointestinal tract. The gut microbiota plays an essential role in regulating whole body energy metabolism and also lipid accumulation, and immunity of host. However, the detail mechanism of which the gut microbiota composition influence obesity development in humans still need deeper investigation owing to the complex pathophysiology of such disease. Recently, the consumption of phenols-rich food has been showed to have physiological function that attribute to improve gut microbiota and benefit body weight management. Here, we review the current knowledge regarding phenolic compounds that regulate the development of obesity and the importance of the axis that link dietary-induced gut microbiota change and metabolic health of host. We also discuss dietary intervention reshaping gut bacterial community to modulate obesity.
\end{abstract}

Keywords: Obesity, Gut microbiota, Phenolic compounds

\section{Contents}

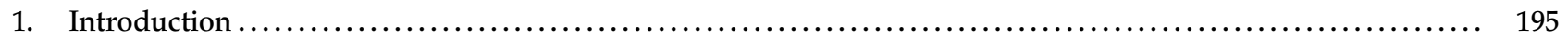

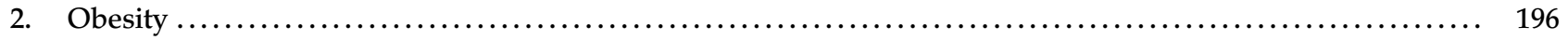

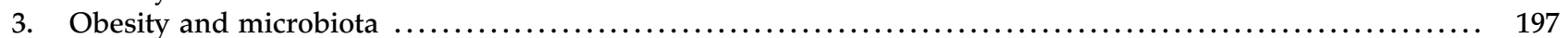

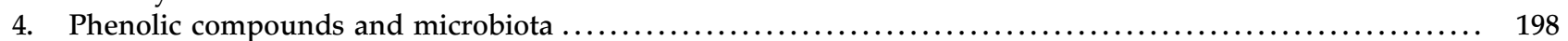

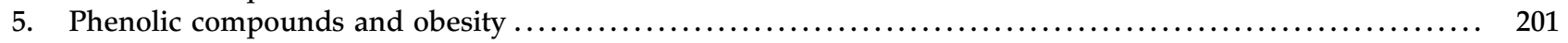

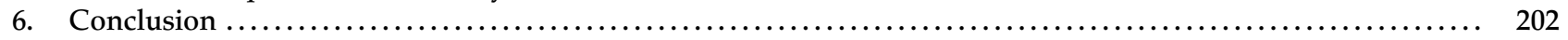

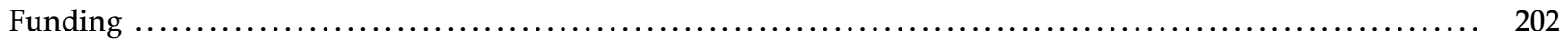

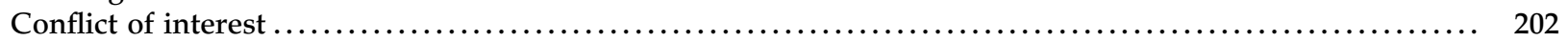

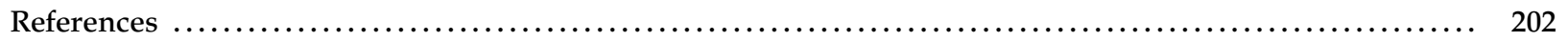

\section{Introduction}

$\mathrm{O}$ besity is a multifactorial chronic disorder, with a global prevalence over 600 million people, and it has also demonstrated a drastically increased over the past decades. According to the
World Health Organization (WHO), people who have a body mass index $(\mathrm{BMI})>30$ are defined as obesity [1]. The common pathway to develop obesity is via excessive calories consumption compared with calories burned; in modern lifestyle, increased intake of fats and sugars, and

Received 11 December 2019; accepted 14 February 2020.

Available online 27 June 2020

* Corresponding author at: Department of Nutrition, Chung Shan Medical University, Taichung, Taiwan.

E-mail addresses: clhsu@csmu.edu.tw (H.-L. Cheng), clhsu@csmu.edu.tw (C.-L. Hsu). 
insufficient physical activity which could eventually lead to obesity. Obesity stimulated the secretion of pro-inflammatory cytokines, which increase the risk of developing insulin resistance and type 2 diabetes mellitus (T2DM) [2-4]. Indeed, obese adipose tissue expansion is correlated with adipocyte hypertrophy and accompanied by altering population of immune cells and elevated adipokines production [5-7]. Recent studies pay much attention on host and environmental factors which might influence energy homeostasis $[4,8-10]$.

It is well known that dietary habits greatly influence the composition and diversity of gut microbiota which play a pivotal role in inflammation and obesity $[11,12]$. Although genetic variants were indeed associated with determination of body weight, the explanation of raising incidence of obesity is fairly modest. Since the evidence of lean mice received transplants from human intestinal microbiota suggested that the obese phenotype can be transfer form donor [13], the manipulation of dietary pattern to microbiota bio-function has sparked considerable interest. Bacteroidetes are able to degrade dietary polysaccharides, metabolizes dietary toxins, against enteric bacterial and particularly specialized to target resistant dietary polymers which are structural components of plants [14,15]. Therefore, diet change in intestine interact with gut microbiota could prevent against obesity and its related complications even liver disease [16-18].
Polyphenols are abundant phytochemicals ubiquitously present in plants such as fruits and vegetables, and exhibit a wild spectrum of pharmacological or nutritional properties and are known to prevent against oxidative stress and disease-related complications $[18,19]$. Based on the difference in chemical structure, polyphenols can be further classified in series main classes, includes phenolic acids, flavonoids, stiblins, curcuminoids, and lignans [20,21]. The bioavailable portion of nature compounds which might exert the action as a potential prebiotics for the maintenance of gut microbiota balance. The potential use of phenolic compounds help preventing obesity via increasing calorie expenditure, decrease adipogenesis, inhibit adipocyte differentiation, and regulate lipid metabolism were systemically documented [22-24]. This review offer a systemic literature related to the role of phenolic compounds in the pharmacological strategies for in vivo, in vitro, and even clinical investigation to assess the anti-obesity effect through modulation of microbiota.

\section{Obesity}

Fundamentally, obesity is a result of excessive fat accumulation which contributed by several factors, including long-term energy consumption, physical inactivity, metabolism, genetic makeup, medication and other environmental factors [25]. Recent studies demonstrate that excessive consumption of high-fat food represents a major environmental factor which is greatly associated with obesity related insulin resistance, glucose intolerance, and cholesterol

\section{Obesity-related complication}

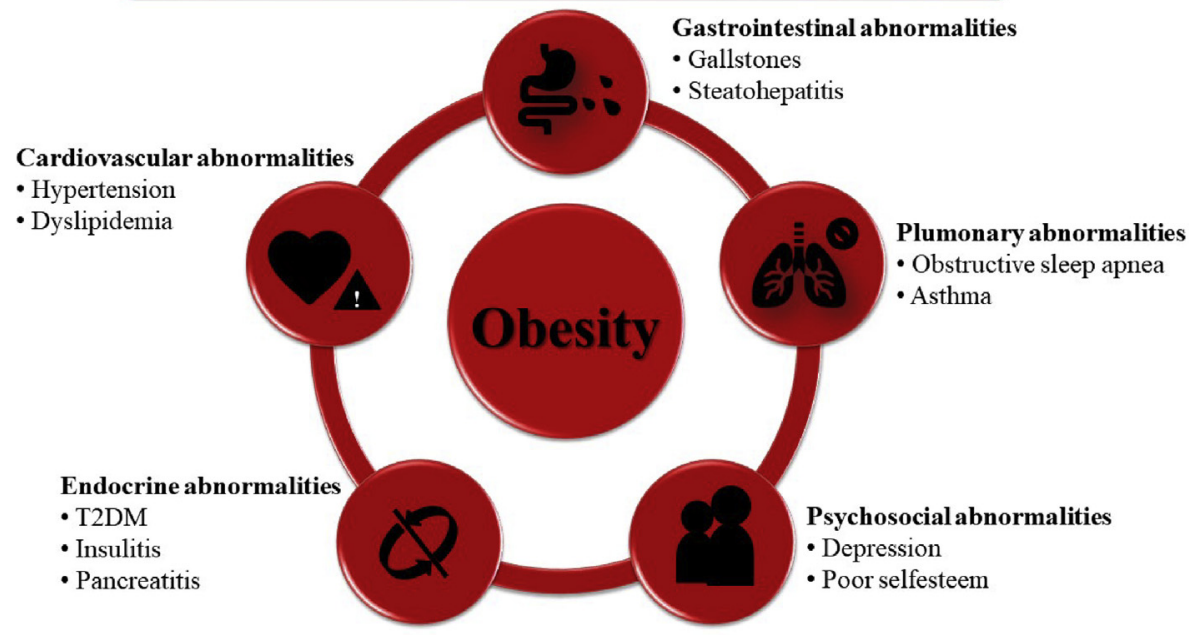

Fig. 1. Schematic representation of obesity and its related complication. The progression of obesity involves multiple physiological changes that may contribute to obesity related co-morbidities. 
metabolism [26-28], which can contributed to the pathogenesis of obesity co-morbidities (Fig. 1). Among environmental factors, gastrointestinal microbiota diversity is believed to affect energy metabolism of host and food intake is described to shape the microbiota composition [29]. As mentioned earlier, germ-free mice with humanized gut microbiome from obese people showed an increased in body weight $[30,31]$; high-fat diet altered gut community, resulting in a changes of microbiome gene expression [32,33]. The adipose tissue was characterized as a passive reservoir for energy storage but also known to play a pivotal role in both autocrine and endocrine level [34-37], glucose homeostasis [38,39], dyslipidemia [40], and inflammation [41]. Obesity increased lipid production and subsequently leaded to free fatty acids released, which cause lipid peroxidation and related lipotoxicity [42]. The intrahepatic lipid accumulation was associated with upregulation of genes involved in lipid catabolism and pro-inflammatory cytokines, such as peroxisome proliferator-activated receptor gamma (PPAR $\gamma$ ) [43] and tumor necrosis factor alpha (TNF- $\alpha$ ). Notably, some studies suggested that inflammatory factors including $\mathrm{TNF}-\alpha$, interleukin $1 \alpha(\mathrm{IL}-1 \alpha)$, interleukin 6 (IL-6), and C-reactive protein (CRP) are linked to impaired insulin resistance and low-grade chronic inflammation of gastrointestinal tract $[44,45]$. Studies on the gene expression of inflammatory factors have revealed that a higher inflammatory status was observed in high-fat diet feeding mice [46]. In addition, adipose tissue excess also increased reactive oxygen species (ROS) formation and free fatty acids release, and subsequently leads to the development of oxidative stress. Oxidative stress is critical to induce DNA methyltransferase 1 (DNMT1) expression and is associated with aberrant DNA methylation [46]. Dietary interventions such as calorie restriction, probiotic supplementation are emerged to modulated gut microbiota and provide valuable impact in therapeutic measurement of metabolic disorders. Recently, nature products, polyphenols have proposed to improve glucose metabolism [47], which also as potent epigenetic active antioxidants and ameliorating oxidative stress. Thus, the used of phenol-rich foods have demonstrated to reduce gut microbiota dysbiosis, improve systemic inflammatory status, and insulin signaling of diet-induced obese mice model, which shows promise as a potential strategy to alleviate obesity-associated diseases.

\section{Obesity and microbiota}

In this part, we will pay our attention on the role of gut microbiota in the pathogenic mechanisms of obesity. Recently, gut microbiota represent a metabolic gateway, through the interaction with host nutritional environment, particularly involved in modulation of chronic condition such as inflammation, energy imbalance and body weight increase $[48,49]$. Human gut microbiota is a complex ecosystem and recent evidence suggested a role of microbiota in fat metabolism.

Diet represents an instrumental factor in alternating the symbiotic relationship of mammalian gut microbiota, which deeply involved in the functions of metabolic diseases. It was suggested that the ratio of Firmicutes/Bacteroidetes represent the imbalance status of gastrointestinal tract, and served as an indicator of health condition [50]. High-sugar or highfat diet consumption, particularly abundant in saturated fatty acids, result in increasing the relative abundance of Firmicutes species at intestinal level in mice models [13]. Data obtained in mice and humans indicated that short-term diet intervention caused a reduction in the abundance of Bacteroidetes within a single day, and these changes may result from the modulation of microbiota gene expression, altered metabolic pathway [51,52]. Similar effect was found in controlled-feeding study that high-fat/low-fiber or low-fat/high-fiber diet intervention rapidly changed gut microbiota composition within $24 \mathrm{~h}$, although the enterotype change required long-term dietary alteration [53]. Moreover, a high-fat and high-sugar dietary modification did not induce obesity and obesity-associated metabolic complication in germ-free mice model [54]; other evidence from microbiota transplantation suggested that an intestinal dysbiosis significantly increase body fat accumulation and particularly insulin resistance [54,55]. These evidences reveal that the obese phenotype is transferrable via the intestinal microbiota in mice.

The direct or indirect effect of high-fat diary consumption cause increase microbiota-produced lipopolysaccharide (LPS), which is regarding as a potential mechanism that triggers the development of inflammation through toll-like receptor 4 (TLR4) dependent pathway. Studies in mice showed that 2-4 weeks consumption of high-fat diet was associated with high LPS level in plasma, which was named metabolic endotoxemia [56]. Furthermore, elevated LPS concentration is linking to reduce intestinal tight junction protein expression, subsequently lead to the lost of intestinal barrier integrity $[57,58]$. Although the interactions between gut microbiota and changes in intestinal epithelium integrity have been documented, the convincing evidence and prominent mechanism that coordinate these observations still needed to be further investigate. 
Table 1. Summary of studies investigating the impact of obesity and associated gut microbiota dysbiosis.

\begin{tabular}{lll}
\hline Subjects & Main Finding & \multicolumn{1}{c}{ References } \\
\hline Overweight and normal-weight pregnant women & $\uparrow$ Bacteroides & [59] \\
& $\uparrow$ Staphylococcus & \\
Obese people assigned to FAT-R Obese people or CARB-R low calorie diet & $\downarrow$ Bacteroidetes & $\uparrow$ Firmicutes \\
& $\uparrow$ Actinobacteria & $\downarrow$ Bacteroidetes \\
Obese and lean twins & $\downarrow$ Bacteroidetes & $\uparrow$ Firmicutes \\
ob/ob and lean ob/+ mice & $\uparrow$ Firmicutes/Bacteroidetes \\
& $\uparrow$ Prevotellaceae \\
C57BL6J (WT) and Fiaf $-/-$ mice & $\downarrow$ Christensenellaceae families \\
Morbidly obese individuals vs. normal weight individuals & $\downarrow$ Rikenellaceae families \\
Twin-pairs from UK population & $\downarrow$ Mollicutes class \\
& $\downarrow$ Dehalobacterium genus \\
& $\downarrow$ Akkermansia genus \\
LifeLines-DEEP participants & $\downarrow$ Christensenellaceae family \\
& $\downarrow$ Tenericutes phylum \\
ob/ob mice and HF-fed male C57BL/6 mice & $\downarrow$ Akkermansia muciniphila \\
\hline
\end{tabular}

Accumulated evidences revealed that obesity is greatly correlated with the richness of gut microbiota, which may lead to the reduction the diversity and composition. Comparison of the differences in microbial composition across the human subjects, diet-induced obese mice and genetic modified animal model clearly showed the dysbiosis in the richness and diversity of gut microbiota (Table 1) [13,59-66]. Except for the evidences of dietary effects on gut microbiota that we mentioned previously, gut microbiota aberrancies appear to mediate the risk of specific disease development. Emerging studies strengthened the interplay between gut microbiota dysbiosis and obesity-related complication and identified several texa that significantly correlated with the development and pathophysiological consequences of diseases both in human subjects and animal models (Table 2) [65,67-70].

\section{Phenolic compounds and microbiota}

High-fat diet-fed mice as a model for the dysbiosis of gut microbiota have been well documented.
Recently, the anti-obesity effect of certain phytochemicals has been explored to reverse high-fat diet-induced change on microbiota composition and intestinal physiology [71]. For instance, the imbalance between Firmicutes to Bacteriodetes is largely linked to obesity development and insulin resistance. Concerning plant secondary metabolites, polyphenols may protect against obesity-associated metabolic complications and even weight loss $[72,73]$. In a similar way, feeding C57BL/6J mice with high-fat diet supplemented with green tea, oolong tea, and black tea infusion for 13 weeks that increased diversity and change the community of gut microbiota, and decrease high-fat diet-induced accumulation of lipids in adipose tissue and increase in body weight [74]. Among these three types of tea, several phenolic compounds including phenolic acids, flavonols and alkaloids, which may modulated the composition of gut microbiota such as Alistipes, Rikenella, Akkermansia etc. Anthocyanins-rich fruits such as grapes and berries show promise as potential inhibitor for reducing inflammatory cytokines through nuclear factor kappa light

Table 2. Summary of studies investigating the relationship of obesity-related complication and gut microbiota profiles.

\begin{tabular}{|c|c|c|c|}
\hline Obesity-relative complication & Subjects & Main Finding & References \\
\hline Dyslipidemia & Human/LifeLines-DEEP cohort & $\downarrow$ Bacteroidetes phylum & {$[65]$} \\
\hline Gastrointestinal abnormalities & $\mathrm{CD}$ and $\mathrm{UC}$ patients & $\begin{array}{l}\downarrow \text { Firmicutes phylum } \\
\uparrow \text { Bacteroidetes phylum }\end{array}$ & [67] \\
\hline Hypertension & HFD/Female SD rat & $\begin{array}{l}\uparrow \text { Firmicutes/Bacteroidetes } \\
\downarrow \text { Lactobacillus genus } \\
\uparrow \text { Verrucomicrobia phylum }\end{array}$ & {$[68]$} \\
\hline Pulmonary abnormalities & OSAHS patients/China & $\downarrow$ Ruminococcaceae & [69] \\
\hline Type 2 diabetes & Human/Iran & $\begin{array}{l}\uparrow \text { Lactobacillales } \\
\downarrow \text { Bacteroides spp }\end{array}$ & {$[70]$} \\
\hline
\end{tabular}




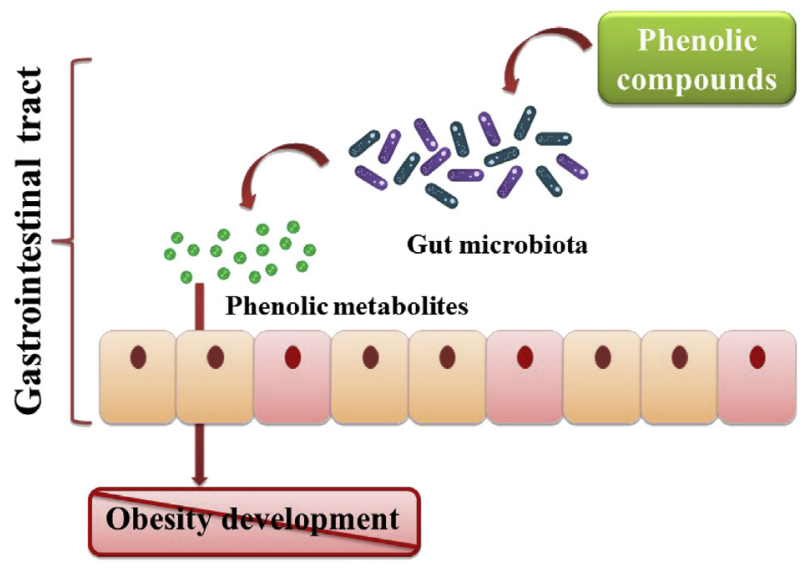

Fig. 2. Crosstalk between the obesity, gut microbiota, and phenolic compounds. The gut microbiota was emerging as a key environmental factor, producing certain secondary metabolites through digestion of phenolic compounds with the consequence of influencing obesity development. chain enhancer of activated B cells (NF- $\kappa$ B) signal transduction and increase PPAR level [75]. Moreover, results of experiments in which diets-based supplement infusion given to moderate fat diet feeding mice reduced fatty acid profiles, inflammatory markers, and deleterious sulfidogenic bacteria; increase the abundance of Akkermansia mucinophila resides in the mucus layer of proximal colon [76]. A combination of quercetin and resveratrol dramatically prevent the development of obesity induced by high-fat diet as well as restore gut microbiota dysbiosis in rats [77]. Other lipid improving effect of betacyanins extract from red pitaya has also shown a negative regulation of Firmicutes; increase the relative abundance of Akkermansia [78].

It was reported that most of dietary polyphenols reached the large intestine, where they are extensively digested by colon microbiota (e.g Bifidobacterium) into simple phenolic compounds, such as phenolic acid. As such, they are absorbed into

Table 3. Summary of the impact of phenolic acid on anti-obesity effects.

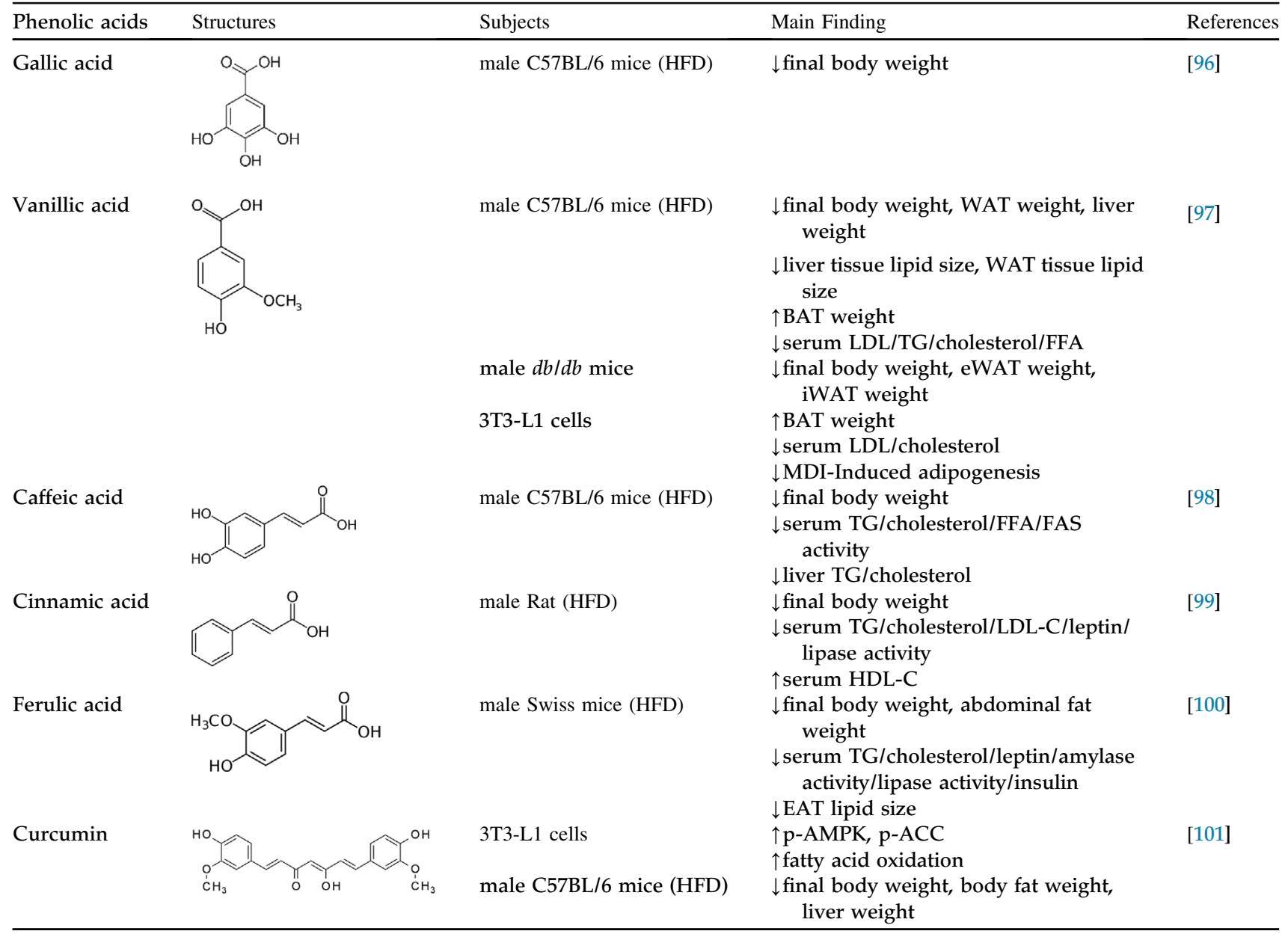


Table 4. Summary of the impact of flavonoids on anti-obesity effects.

\begin{tabular}{|c|c|c|c|c|}
\hline Flavonoids & Structures & Subjects & Main Finding & References \\
\hline \multirow[t]{2}{*}{ Quercetin } & & male C57BL/6 mice (HFD) & $\begin{array}{l}\downarrow \text { final body weight, EAT weight, } \\
\text { SAT weight }\end{array}$ & [102] \\
\hline & & & $\begin{array}{l}\downarrow \text { EAT adipocyte size } \\
\downarrow \text { serum leptin } \\
\uparrow \text { EAT p-AMPK, SIRT1 } \\
\uparrow \text { BAT Ucp } 1\end{array}$ & \\
\hline Isorhamnetin & & 3T3-L1 cells & $\begin{array}{l}\downarrow 3 \mathrm{~T} 3-\mathrm{L} 1 \text { adipocyte differentiation } \\
\downarrow P P A R-\gamma, C / E B P-\alpha, \text { Krox 20, PGC- } \\
\quad \text { 1, Adiponetin }\end{array}$ & [109] \\
\hline Myricetin & & male C57BL/6 mice (HFD) & $\begin{array}{l}\downarrow \text { final body weight, EAT weight, } \\
\text { SAT weight, PAT weight } \\
\downarrow \text { EAT adipocyte size } \\
\downarrow \text { serum TG/leptin/TNF- } \alpha / \text { insu- } \\
\quad \text { lin/MDA } \\
\uparrow \text { serum adiponectin/GPX/T- } \\
\quad \text { AOC } \\
\downarrow \text { EAT } P P A R \gamma, C / E B P \alpha, S R E B P-1 c\end{array}$ & [103] \\
\hline Kaempferol & & male C57BL/6 mice (HFD) & $\begin{array}{l}\downarrow \text { final body weight, EAT weight, } \\
\quad \text { VAT weight, PAT weight } \\
\downarrow \text { serum TG/insulin/leptin } \\
\downarrow \text { liver TG } \\
\uparrow \text { liver FAS activity } \\
\downarrow \text { liver PPAR } \gamma\end{array}$ & [104] \\
\hline Epicatechin & & male C57BL/6 mice (HFD) & $\begin{array}{l}\downarrow \text { final body weight } \\
\downarrow \text { serum TG/FFA/insulin/leptin } \\
\downarrow \text { liver p-IKK } \alpha, \text { p-JNK, PTP1B } \\
\downarrow \text { EAT p-IKK } \alpha, \text { p-JNK, PTP1B }\end{array}$ & [105] \\
\hline Daidzein & & male ICR mice (HFD) & $\begin{array}{l}\downarrow \text { final body weight, EAT weight, } \\
\text { MAT weight, PAT weight, } \\
\text { SAT weight } \\
\downarrow \text { plasma cholesterol/LDL-C/FFA } \\
\uparrow \text { plasma HDL-C } \\
\downarrow \text { liver cholesterol/FFA }\end{array}$ & [106] \\
\hline
\end{tabular}

blood circulation by the portal vein that may have effect on peripheral tissue and contributed to local and systemic health $[14,79]$. Taken into account the phenol-derived microbial metabolites obtained from parents compounds such as epigallocatechin gallate (EGCG), chlorogenic acid, anthocyanins, and procyanidins which were reported to determine specific gut microbiota species that generates catalytic abilities to processing phenolic structure and consequently provided an antibacterial properties [80]. For example, degradation of polymers into oligomers and the gallate esters of EGCG convert into pyrogallol by decarboxylation, which is further enhancing the growth of Bifidobacterium and clostridium. From anthocyanins, gallic acid, and syringic acid are produced by Lactobacteria and Bifidobacteria that may responsible for increasing the population of Bifidobacterium species [81,82]. In summary, theses evidences revealed that the changes of microbiota upon phenolic compounds supplementation which may correlate with its biometabolites advantages.

Collectively, several features of dietary phytochemicals have been previously investigated in the 
Table 5. Summary of the impact of other phenolic compounds on anti-obesity effects.

\begin{tabular}{|c|c|c|c|c|}
\hline $\begin{array}{l}\text { Other phenolic } \\
\text { compounds }\end{array}$ & Structures & Subjects & Main Finding & References \\
\hline Piceatannol & & $\begin{array}{l}\text { male C57BL/6 } \\
\text { mice (HFD) }\end{array}$ & $\begin{array}{l}\downarrow \text { final body weight, PAT weight, RAT } \\
\text { weight }\end{array}$ & {$[107]$} \\
\hline Tannic acid & $\mathrm{OH}$ & 3T3-L1 cells & $\begin{array}{l}\downarrow \text { PAT adipocyte size } \\
\downarrow \text { serum cholesterol } \\
\uparrow \text { serum HDL-C } \\
\uparrow \text { liver pAMPK } \alpha, \text { pACC } \\
\downarrow \text { liver PPAR } \gamma, \text { C/EBP } \alpha, \text { FAS } \\
\downarrow \text { adipogenesis } \\
\downarrow \text { PPAR } \gamma, \text { FAS }\end{array}$ & [108] \\
\hline
\end{tabular}

literature, including the modulation of brown and beige adipose tissue recruitment and metabolism. Hence, the phenolic compounds that are digested/ absorbed by gut microbiota showed the potential effects on healthy status due to their bioactivities. Intriguingly, the bioavailable proportion is a triangular relationship between dietary ingredients, human healthy, and gut microbial ecosystem (Fig. 2). However, the precise mechanisms responsible for the metabolic improvement of bioactive compounds have not yet been clearly elucidated, and are needed further investigation.

\section{Phenolic compounds and obesity}

According to structure properties, phenols are further divided into phenolic acids, flavonoids, stilbenes and lignans, which are distributed in fruits and vegetables of plant sources. Biological activities of phenolic substances have been studied extensively in recent years. Numerous epidemiological studies suggest that the consumption of phenolicrich foods may reduce the incidence of chronic diseases, including obesity and obesity-related complications such as insulin resistance, gastrointestinal abnormalities, and dyslipidaemia [83,84]. Evidence from cellular study demonstrated that certain dietary polyphenols (catechins, EGCG, resveratrol, and curcumin) reduced adipocytes viability, proliferation, and differentiation, and shows further antioxidant effect and increased lipolysis [85-87]. Moreover, tea polyphenols was demonstrated to dose dependently retard body weight gain and fat accumulation in high-fat diet induced animal model. There is also evidence of population-based cohort studies by which polyphenols contained food protect against the incident of obesity that may associated with nutrient-dense source of polyphenol intake rather than energy-dense, which eventually lead to a reduction of calorie intake. Compelling evidence elucidated a significant correlation of flavonoids between obesity and weight management [88].

Green tea catechin, such as EGCG shows strong anti-oxidant and anti-obesity effects by increasing lipolysis, promoting energy expenditure and inhibit appetite, though weight management have been proposed to be a coefficient with caffeine intake by conducting meta-analysis of cohort study [89]. Among the compounds of plants, including gingernone A, quercetin, piceatannol, and cinnamon polyphenol extract has been described as suppressor to adipogenesis, inhibited adipose tissue inflammation through modulation of signaling pathway in high-fat diet-induced obese animal model [90-93]. Recently, microRNA (miRNAs) are found to closely correlate with obesity related inflammatory response through the regulation of miR-221, miR-222, and miR-155 and subsequently increased IL- 6 and TNF- $\alpha$ expression [94]. Similar effects appear to be present for proanthocyanidins extracts also demonstrated to have inhibitory effects on lipogenesis by suppressing the hepatic lipid regulatory miR-122 in obese rat [95].

Although the anti-inflammatory and antioxidant activities of intervention studies suggest prevention effect related to obesity in phenols compounds consumption, they must be complete understanding in the maintenance of health status and beneficial level of intake. Excepted for these evidences mentioned before, Tables 3-5 categorizing studies based on phenolic acid, flavonoids, and other 
phenolics that showed an anti-obesity effect and involved several signal transductions and elicit cellular responses, subsequently lead to body weight loss [96-109]. Although such phenol-base studies have wildly investigated, the dose variation and treatment frequency in-vivo and in-vitro still needed to be further confirmed.

\section{Conclusion}

This narrative review showed a comprehensive view of the preventive role of phenolic compounds in the obesity development through modulating gut microbiota. Dietary habit and modest lifestyle play a crucial role for the prevention and management of obesity. Growing evidences suggested the role of dietary change and secondary lifestyle in obesity prevention. Although the energy restriction is the most common way to manage obesity, bioactive compounds in native plants, such as phenols, shows its antiobesity properties. There is substantial evidence to support the effects of gut microbiota composition for the catabolism and absorption of bio-metabolites derived from dietary phenols. Moreover, the overall composition of microbiota at baseline might modulate gut microbiota diversity after dietary intervention. Studies in vitro and in vivo have used to reveal the benefit effects of phenolic compound amount dietary patterns as well as regulated gut microbiota ecology. Concerning the multitude of phenolic compounds, with its structure complexity, resident of absorption and catalytic roles in gut microbiota that make it need deeper insight into detail mechanism, and further human clinical trial are needed to elucidate the safety and health-promoting implications.

\section{Funding}

This research work was supported by the grant MOST 107-2320-B-040-019-MY3 from the Ministry of Science and Technology (MOST), Taiwan.

\section{Conflict of interest}

The authors declare that no conflicts of interest exist.

\section{References}

[1] Ghoorah K, Campbell P, Kent A, Maznyczka A, Kunadian V. Obesity and cardiovascular outcomes: a review. Eur Heart J Acute Cardiovasc Care 2016;5:77-85.

[2] Hotamisligil GS. Inflammation and metabolic disorders. Nature 2006;444:860-7.

[3] Parker LC, Prince LR, Sabroe I. Translational mini-review series on Toll-like receptors: networks regulated by Toll- like receptors mediate innate and adaptive immunity. Clin Exp Immunol 2007;147:199-207.

[4] Wright SD, Ramos RA, Tobias PS, Ulevitch RJ, Mathison JC. CD14, a receptor for complexes of lipopolysaccharide (LPS) and LPS binding protein. Science 1990;249:1431-3.

[5] Sethi JK, Vidal-Puig AJ. Thematic review series: adipocyte biology. Adipose tissue function and plasticity orchestrate nutritional adaptation. J Lipid Res 2007;48:1253-62.

[6] Springer M, Moco S. Resveratrol and its human metabolites-effects on metabolic health and obesity. Nutrients 2019;11.

[7] Correa TA, Rogero MM. Polyphenols regulating microRNAs and inflammation biomarkers in obesity. Nutrition 2019;59:150-7.

[8] Choi BK, Park SB, Lee DR, Lee HJ, Jin YY, Yang SH, et al. Green coffee bean extract improves obesity by decreasing body fat in high-fat diet-induced obese mice. Asian Pac J Trop Med 2016;9:635-43.

[9] Qin N, Chen Y, Jin MN, Zhang C, Qiao W, Yue XL, et al. Anti-obesity and anti-diabetic effects of flavonoid derivative (Fla-CN) via microRNA in high fat diet induced obesity mice. Eur J Pharmaceut Sci 2016;82:52-63.

[10] Naowaboot J, Piyabhan P, Munkong N, Parklak W, Pannangpetch P. Ferulic acid improves lipid and glucose homeostasis in high-fat diet-induced obese mice. Clin Exp Pharmacol Physiol 2016;43:242-50.

[11] Conlon MA, Bird AR. The impact of diet and lifestyle on gut microbiota and human health. Nutrients 2014;7:17-44.

[12] Walker AW, Ince J, Duncan SH, Webster LM, Holtrop G, Ze $\mathrm{X}$, et al. Dominant and diet-responsive groups of bacteria within the human colonic microbiota. ISME J 2011;5: 220-30.

[13] Ley RE, Backhed F, Turnbaugh P, Lozupone CA Knight RD, Gordon JI. Obesity alters gut microbial ecology. Proc Natl Acad Sci U S A 2005;102:11070-5.

[14] Espin JC, Gonzalez-Sarrias A, Tomas-Barberan FA. The gut microbiota: a key factor in the therapeutic effects of (poly) phenols. Biochem Pharmacol 2017;139:82-93.

[15] Bindels LB, Delzenne NM, Cani PD, Walter J. Towards a more comprehensive concept for prebiotics. Nat Rev Gastroenterol Hepatol 2015;12:303-10.

[16] Neyrinck AM, Etxeberria U, Taminiau B, Daube G, Van Hul M, Everard A, et al. Rhubarb extract prevents hepatic inflammation induced by acute alcohol intake, an effect related to the modulation of the gut microbiota. Mol Nutr Food Res 2017;61.

[17] Alard J, Lehrter V, Rhimi M, Mangin I, Peucelle V Abraham AL, et al. Beneficial metabolic effects of selected probiotics on diet-induced obesity and insulin resistance in mice are associated with improvement of dysbiotic gut microbiota. Environ Microbiol 2016;18:1484-97.

[18] Portune KJ, Benitez-Paez A, Del Pulgar EM, Cerrudo V, Sanz Y. Gut microbiota, diet, and obesity-related disordersThe good, the bad, and the future challenges. Mol Nutr Food Res 2017;61.

[19] Kumar N, Goel N. Phenolic acids: natural versatile molecules with promising therapeutic applications. Biotechnol Rep (Amst) 2019;24:e00370.

[20] de Paulo Farias D, Neri-Numa IA, de Araujo FF, Pastore GM. A critical review of some fruit trees from the Myrtaceae family as promising sources for food applications with functional claims. Food Chem 2019;306:125630.

[21] Desai S, Tatke P. Phytochemical markers: classification, applications and isolation. Curr Pharmaceut Des 2019;25 2491-8.

[22] Roshan H, Nikpayam O, Sedaghat M, Sohrab G. Effects of green coffee extract supplementation on anthropometric indices, glycaemic control, blood pressure, lipid profile, insulin resistance and appetite in patients with the metabolic syndrome: a randomised clinical trial. Br J Nutr 2018; 119:250-8. 
[23] Song SJ, Choi S, Park T. Decaffeinated green coffee bean extract attenuates diet-induced obesity and insulin resistance in mice. Evid Based Complement Alternat Med 2014; 2014:718379.

[24] Keshari AK, Kumar G, Kushwaha PS, Bhardwaj M, Kumar P, Rawat A, et al. Isolated flavonoids from Ficus racemosa stem bark possess antidiabetic, hypolipidemic and protective effects in albino Wistar rats. J Ethnopharmacol 2016;181:252-62.

[25] Gonzalez-Muniesa P, Martinez-Gonzalez MA, Hu FB, Despres JP, Matsuzawa Y, Loos RJF, et al. Obesity. Nat Rev Dis Primers 2017;3:17034.

[26] Saltiel AR, Kahn CR. Insulin signalling and the regulation of glucose and lipid metabolism. Nature 2001;414:799-806.

[27] Boulange CL, Neves AL, Chilloux J, Nicholson JK, Dumas ME. Impact of the gut microbiota on inflammation, obesity, and metabolic disease. Genome Med 2016;8:42.

[28] Djalalinia S, Qorbani M, Peykari N, Kelishadi R. Health impacts of obesity. Pak J Med Sci 2015;31:239-42.

[29] Barathikannan K, Chelliah R, Rubab M, Daliri EB, Elahi F, Kim DH, et al. Gut microbiome modulation based on probiotic application for anti-obesity: a review on efficacy and validation. Microorganisms 2019;7.

[30] Turnbaugh PJ, Ley RE, Mahowald MA, Magrini V, Mardis ER, Gordon JI. An obesity-associated gut microbiome with increased capacity for energy harvest. Nature 2006; 444:1027-31.

[31] Ridaura VK, Faith JJ, Rey FE, Cheng J, Duncan AE, Kau AL, et al. Gut microbiota from twins discordant for obesity modulate metabolism in mice. Science 2013;341:1241214.

[32] Fleissner CK, Huebel N, Abd El-Bary MM, Loh G, Klaus S, Blaut M. Absence of intestinal microbiota does not protect mice from diet-induced obesity. Br J Nutr 2010;104:919-29.

[33] Janssens PL, Penders J, Hursel R, Budding AE, Savelkoul PH, Westerterp-Plantenga MS. Long-term green tea supplementation does not change the human gut microbiota. PloS One 2016;11:e0153134.

[34] Villarroya F, Cereijo R, Villarroya J, Giralt M. Brown adipose tissue as a secretory organ. Nat Rev Endocrinol 2017; 13:26-35.

[35] Villarroya F, Gavalda-Navarro A, Peyrou M, Villarroya J, Giralt M. The lives and times of Brown adipokines. Trends Endocrinol Metab 2017;28:855-67.

[36] Wang GX, Zhao XY, Lin JD. The brown fat secretome: metabolic functions beyond thermogenesis. Trends Endocrinol Metab 2015;26:231-7.

[37] Kershaw EE, Flier JS. Adipose tissue as an endocrine organ. J Clin Endocrinol Metab 2004;89:2548-56.

[38] Kemper JK, Xiao Z, Ponugoti B, Miao J, Fang S, Kanamaluru D, et al. FXR acetylation is normally dynamically regulated by p300 and SIRT1 but constitutively elevated in metabolic disease states. Cell Metabol 2009;10: 392-404.

[39] Lin HV, Frassetto A, Kowalik Jr EJ, Nawrocki AR, Lu MM, Kosinski JR, et al. Butyrate and propionate protect against diet-induced obesity and regulate gut hormones via free fatty acid receptor 3-independent mechanisms. PloS One 2012; 7:e35240

[40] Jain KS, Kathiravan MK, Somani RS, Shishoo CJ. The biology and chemistry of hyperlipidemia. Bioorg Med Chem 2007;15:4674-99.

[41] Reyes-Farias M, Vasquez K, Ovalle-Marin A, Fuentes F, Parra C, Quitral V, et al. Chilean native fruit extracts inhibit inflammation linked to the pathogenic interaction between adipocytes and macrophages. J Med Food 2015;18:601-8.

[42] Chiang JYL. Targeting bile acids and lipotoxicity for NASH treatment. Hepatol Commun 2017;1:1002-4.

[43] Shoelson SE, Herrero L, Naaz A. Obesity, inflammation, and insulin resistance. Gastroenterology 2007;132:2169-80.

[44] Fain JN, Madan AK, Hiler ML, Cheema P, Bahouth SW. Comparison of the release of adipokines by adipose tissue, adipose tissue matrix, and adipocytes from visceral and subcutaneous abdominal adipose tissues of obese humans Endocrinology 2004;145:2273-82.

[45] Maury E, Ehala-Aleksejev K, Guiot Y, Detry R, Vandenhooft A, Brichard SM. Adipokines oversecreted by omental adipose tissue in human obesity. Am J Physiol Endocrinol Metab 2007;293:E656-65.

[46] Remely M, Ferk F, Sterneder S, Setayesh T, Roth S, Kepcija T, et al. EGCG prevents high fat diet-induced changes in gut microbiota, decreases of DNA strand breaks, and changes in expression and DNA methylation of Dnmt and MLH1 in C57BL/6J male mice. Oxid Med Cell Longey 2017;2017:3079148

[47] Vitale M, Vaccaro O, Masulli M, Bonora E, Del Prato S, Giorda CB, et al. Polyphenol intake and cardiovascular risk factors in a population with type 2 diabetes: the TOSCA.IT study. Clin Nutr 2017;36:1686-92.

[48] Lynch SV, Pedersen O. The human intestinal microbiome in health and disease. N Engl J Med 2016;375:2369-79.

[49] Vaiserman AM, Koliada AK, Marotta F. Gut microbiota: a player in aging and a target for anti-aging intervention. Ageing Res Rev 2017;35:36-45.

[50] Remely M, Tesar I, Hippe B, Gnauer S, Rust P, Haslberger AG. Gut microbiota composition correlates with changes in body fat content due to weight loss. Benef Microbes 2015;6:431-9.

[51] Wu GD, Chen J, Hoffmann C, Bittinger K, Chen YY, Keilbaugh SA, et al. Linking long-term dietary patterns with gut microbial enterotypes. Science 2011;334:105-8.

[52] David LA, Maurice CF, Carmody RN, Gootenberg DB, Button JE, Wolfe BE, et al. Diet rapidly and reproducibly alters the human gut microbiome. Nature 2014:505:559-63.

[53] Faith JJ, Guruge JL, Charbonneau M, Subramanian S, Seedorf H, Goodman AL, et al. The long-term stability of the human gut microbiota. Science 2013;341:1237439.

[54] Backhed F, Manchester JK, Semenkovich CF, Gordon JI Mechanisms underlying the resistance to diet-induced obesity in germ-free mice. Proc Natl Acad Sci U S A 2007; 104:979-84.

[55] Shin NR, Lee JC, Lee HY, Kim MS, Whon TW, Lee MS, et al. An increase in the Akkermansia spp. population induced by metformin treatment improves glucose homeostasis in diet-induced obese mice. Gut 2014;63:727-35.

[56] Cani PD, Bibiloni R, Knauf C, Waget A, Neyrinck AM, Delzenne NM, et al. Changes in gut microbiota control metabolic endotoxemia-induced inflammation in high-fat diet-induced obesity and diabetes in mice. Diabetes 2008;57: 1470-81.

[57] Martinez-Medina M, Denizot J, Dreux N, Robin F, Billard E, Bonnet $\mathrm{R}$, et al. Western diet induces dysbiosis with increased E coli in CEABAC10 mice, alters host barrier function favouring AIEC colonisation. Gut 2014;63:116-24.

[58] Morales P, Fujio S, Navarrete P, Ugalde JA, Magne F, Carrasco-Pozo C, et al. Impact of dietary lipids on colonic function and microbiota: an experimental approach involving orlistat-induced fat malabsorption in human volunteers. Clin Transl Gastroenterol 2016;7:e161.

[59] Collado MC, Isolauri E, Laitinen K, Salminen S. Distinct composition of gut microbiota during pregnancy in overweight and normal-weight women. Am J Clin Nutr 2008;88:894-9.

[60] Ley RE, Turnbaugh PJ, Klein S, Gordon JI. Microbial ecology: human gut microbes associated with obesity. Nature 2006;444:1022-3.

[61] Turnbaugh PJ, Hamady M, Yatsunenko T, Cantarel BL, Duncan A, Ley RE, et al. A core gut microbiome in obese and lean twins. Nature 2009;457:480-4.

[62] Backhed F, Ding H, Wang T, Hooper LV, Koh GY, Nagy A, et al. The gut microbiota as an environmental factor that regulates fat storage. Proc Natl Acad Sci U S A 2004;101: 15718-23.

[63] Zhang H, DiBaise JK, Zuccolo A, Kudrna D, Braidotti M, $\mathrm{Yu}$ Y, et al. Human gut microbiota in obesity and after gastric bypass. Proc Natl Acad Sci U S A 2009;106:2365-70. 
[64] Goodrich JK, Waters JL, Poole AC, Sutter JL, Koren O, Blekhman R, et al. Human genetics shape the gut microbiome. Cell 2014;159:789-99.

[65] Fu J, Bonder MJ, Cenit MC, Tigchelaar EF, Maatman A, Dekens JA, et al. The gut microbiome contributes to a substantial proportion of the variation in blood lipids. Circ Res 2015;117:817-24.

[66] Everard A, Belzer C, Geurts L, Ouwerkerk JP, Druart C, Bindels LB, et al. Cross-talk between Akkermansia muciniphila and intestinal epithelium controls diet-induced obesity. Proc Natl Acad Sci U S A 2013;110:9066-71.

[67] Walker AW, Sanderson JD, Churcher C, Parkes GC, Hudspith BN, Rayment N, et al. High-throughput clone library analysis of the mucosa-associated microbiota reveals dysbiosis and differences between inflamed and noninflamed regions of the intestine in inflammatory bowel disease. BMC Microbiol 2011;11:7.

[68] Hsu CN, Hou CY, Lee CT, Chan JYH, Tain YL. The interplay between maternal and post-weaning high-fat diet and gut microbiota in the developmental programming of hypertension. Nutrients 2019;11.

[69] Ko CY, Liu QQ, Su HZ, Zhang HP, Fan JM, Yang JH, et al. Gut microbiota in obstructive sleep apnea-hypopnea syndrome: disease-related dysbiosis and metabolic comorbidities. Clin Sci (Lond) 2019;133:905-17.

[70] Sedighi M, Razavi S, Navab-Moghadam F, Khamseh ME, Alaei-Shahmiri F, Mehrtash A, et al. Comparison of gut microbiota in adult patients with type 2 diabetes and healthy individuals. Microb Pathog 2017;111:362-9.

[71] Cheng M, Zhang X, Miao Y, Cao J, Wu Z, Weng P. The modulatory effect of (-)-epigallocatechin 3-O-(3-O-methyl) gallate (EGCG3"Me) on intestinal microbiota of high fat diet-induced obesity mice model. Food Res Int 2017;92: 9-16.

[72] Han LK, Takaku T, Li J, Kimura Y, Okuda H. Anti-obesity action of oolong tea. Int J Obes Relat Metab Disord 1999;23: 98-105.

[73] Zhang X, Wu Z, Weng P. Antioxidant and hepatoprotective effect of (-)-epigallocatechin 3-O-(3-O-methyl) gallate (EGCG3"Me) from Chinese oolong tea. J Agric Food Chem 2014;62:10046-54

[74] Liu Z, Chen Z, Guo H, He D, Zhao H, Wang Z, et al. The modulatory effect of infusions of green tea, oolong tea, and black tea on gut microbiota in high-fat-induced obese mice. Food Funct 2016;7:4869-79.

[75] Collins B, Hoffman J, Martinez K, Grace M, Lila MA, Cockrell C, et al. A polyphenol-rich fraction obtained from table grapes decreases adiposity, insulin resistance and markers of inflammation and impacts gut microbiota in high-fat-fed mice. J Nutr Biochem 2016;31:150-65.

[76] Baldwin J, Collins B, Wolf PG, Martinez K, Shen W, Chuang CC, et al. Table grape consumption reduces adiposity and markers of hepatic lipogenesis and alters gut microbiota in butter fat-fed mice. J Nutr Biochem 2016;27:123-35.

[77] Zhao L, Zhang Q, Ma W, Tian F, Shen H, Zhou M. A combination of quercetin and resveratrol reduces obesity in high-fat diet-fed rats by modulation of gut microbiota. Food Funct 2017:8:4644-56.

[78] Song H, Chu Q, Yan F, Yang Y, Han W, Zheng X. Red pitaya betacyanins protects from diet-induced obesity, liver steatosis and insulin resistance in association with modulation of gut microbiota in mice. J Gastroenterol Hepatol 2016;31: 1462-9.

[79] Avila-Galvez MA, Gonzalez-Sarrias A, Espin JC. In vitro research on dietary polyphenols and health: a call of caution and a guide on how to proceed. J Agric Food Chem 2018:66:7857-8.

[80] Masumoto S, Terao A, Yamamoto Y, Mukai T, Miura T, Shoji T. Non-absorbable apple procyanidins prevent obesity associated with gut microbial and metabolomic changes. Sci Rep 2016;6:31208.

[81] Boto-Ordonez M, Urpi-Sarda M, Queipo-Ortuno MI, Tulipani S, Tinahones FJ, Andres-Lacueva C. High levels of
Bifidobacteria are associated with increased levels of anthocyanin microbial metabolites: a randomized clinical trial. Food Funct 2014;5:1932-8.

[82] Gwiazdowska D, Jus K, Jasnowska-Malecka J, Kluczynska K. The impact of polyphenols on Bifidobacterium growth. Acta Biochim Pol 2015;62:895-901.

[83] Ballard CR, Galvao TF, Cazarin CBB, Marostica Jr MR. Effects of polyphenol-rich fruit extracts on diet-induced obesity in rodents: systematic review and meta-analysis. Curr Pharmaceut Des 2019;25:3484-97.

[84] Dryden GW, Song M, McClain C. Polyphenols and gastrointestinal diseases. Curr Opin Gastroenterol 2006;22: 165-70.

[85] Dias MM, Martino HS, Noratto G, Roque-Andrade A, Stringheta PC, Talcott S, et al. Anti-inflammatory activity of polyphenolics from acai (Euterpe oleracea Martius) in intestinal myofibroblasts CCD-18Co cells. Food Funct 2015;6: 3249-56.

[86] Milenkovic D, Jude B, Morand C. miRNA as molecular target of polyphenols underlying their biological effects. Free Radic Biol Med 2013;64:40-51.

[87] Tsang WP, Kwok TT. Epigallocatechin gallate up-regulation of miR-16 and induction of apoptosis in human cancer cells. Nutr Biochem 2010;21:140-6.

[88] Wang S, Moustaid-Moussa N, Chen L, Mo H, Shastri A, $\mathrm{Su}$ R, et al. Novel insights of dietary polyphenols and obesity. J Nutr Biochem 2014;25:1-18.

[89] Dulloo AG, Duret C, Rohrer D, Girardier L, Mensi N, Fathi M, et al. Efficacy of a green tea extract rich in catechin polyphenols and caffeine in increasing 24-h energy expenditure and fat oxidation in humans. Am J Clin Nutr 1999;70:1040-5.

[90] Tuzcu Z, Orhan C, Sahin N, Juturu V, Sahin K. Cinnamon polyphenol extract inhibits hyperlipidemia and inflammation by modulation of transcription factors in high-fat dietfed rats. Oxid Med Cell Longev 2017;2017:1583098.

[91] Seo MJ, Lee YJ, Hwang JH, Kim KJ, Lee BY. The inhibitory effects of quercetin on obesity and obesity-induced inflammation by regulation of MAPK signaling. J Nutr Biochem 2015;26:1308-16.

[92] Suk S, Kwon GT, Lee E, Jang WJ, Yang H, Kim JH, et al Gingerenone A, a polyphenol present in ginger, suppresses obesity and adipose tissue inflammation in high-fat diet-fed mice. Mol Nutr Food Res 2017;61.

[93] Kershaw J, Kim KH. The therapeutic potential of piceatannol, a natural stilbene, in metabolic diseases: a review. J Med Food 2017;20:427-38.

[94] Ortega FJ, Moreno M, Mercader JM, Moreno-Navarrete JM, Fuentes-Batllevell N, Sabater M, et al. Inflammation triggers specific microRNA profiles in human adipocytes and macrophages and in their supernatants. Clin Epigenetics 2015;7:49.

[95] Baselga-Escudero L, Blade C, Ribas-Latre A, Casanova E, Suarez M, Torres JL, et al. Resveratrol and EGCG bind directly and distinctively to miR-33a and miR-122 and modulate divergently their levels in hepatic cells. Nucleic Acids Res 2014:42:882-92.

[96] Doan KV, Ko CM, Kinyua AW, Yang DJ, Choi YH, Oh IY, et al. Gallic acid regulates body weight and glucose homeostasis through AMPK activation. Endocrinology 2015; 156:157-68.

[97] Jung Y, Park J, Kim HL, Sim JE, Youn DH, Kang J, et al. Vanillic acid attenuates obesity via activation of the AMPK pathway and thermogenic factors in vivo and in vitro. FASEB J 2018;32:1388-402.

[98] Liao CC, Ou TT, Wu CH, Wang CJ. Prevention of dietinduced hyperlipidemia and obesity by caffeic acid in C57BL/6 mice through regulation of hepatic lipogenesis gene expression. J Agric Food Chem 2013;61:11082-8.

[99] Mnafgui K, Derbali A, Sayadi S, Gharsallah N, Elfeki A, Allouche N. Anti-obesity and cardioprotective effects of cinnamic acid in high fat diet- induced obese rats. J Food Sci Technol 2015:52:4369-77. 
[100] de Melo TS, Lima PR, Carvalho KM, Fontenele TM, Solon FR, Tome AR, et al. Ferulic acid lowers body weight and visceral fat accumulation via modulation of enzymatic, hormonal and inflammatory changes in a mouse model of high-fat diet-induced obesity. Braz J Med Biol Res 2017;50: e5630.

[101] Ejaz A, Wu D, Kwan P, Meydani M. Curcumin inhibits adipogenesis in 3T3-L1 adipocytes and angiogenesis and obesity in C57/BL mice. J Nutr 2009;139:919-25.

[102] Dong J, Zhang X, Zhang L, Bian HX, Xu N, Bao B, et al. Quercetin reduces obesity-associated ATM infiltration and inflammation in mice: a mechanism including AMPKalpha1/SIRT1. J Lipid Res 2014;55:363-74.

[103] Su HM, Feng LN, Zheng XD, Chen W. Myricetin protects against diet-induced obesity and ameliorates oxidative stress in C57BL/6 mice. J Zhejiang Univ - Sci B 2016;17: 437-46.

[104] Zang Y, Zhang L, Igarashi K, Yu C. The anti-obesity and anti-diabetic effects of kaempferol glycosides from unripe soybean leaves in high-fat-diet mice. Food Funct 2015;6: 834-41.

[105] Cremonini E, Bettaieb A, Haj FG, Fraga CG, Oteiza PI. (-)-Epicatechin improves insulin sensitivity in high fat dietfed mice. Arch Biochem Biophys 2016;599:13-21.

[106] Guo Y, Wu G, Su X, Yang H, Zhang J. Antiobesity action of a daidzein derivative on male obese mice induced by a high-fat diet. Nutr Res 2009;29:656-63.

[107] Tung YC, Lin YH, Chen HJ, Chou SC, Cheng AC, Kalyanam N, et al. Piceatannol exerts anti-obesity effects in C57BL/6 mice through modulating adipogenic proteins and gut microbiota. Molecules 2016;21.

[108] Fan H, Wu D, Tian W, Ma X. Inhibitory effects of tannic acid on fatty acid synthase and 3T3-L1 preadipocyte. Biochim Biophys Acta 2013;1831:1260-6.

[109] Lee J, Jung E, Lee J, Kim S, Huh S, Kim Y, et al. Isorhamnetin represses adipogenesis in 3T3-L1 cells. Obesity (Silver Spring) 2009;17:226-32. 